\title{
Discurso del Sr. Presidente de la Asociación Argentina de Cirugía ${ }^{1}$ Asociación Argentina de Cirugía Presidential Address
}

\author{
Alejandro M. de la Torre
}

Buenas tardes, autoridades presentes, nuevos MAAC*, colegas, familiares, señoras y señores:

Hace 87 años, cuando se fundó la Asociación Argentina de Cirugía, se fijó como Misión, y así figura aún en sus estatutos, Fomentar el bien común sin fines de lucro.

Estimular la capacitación profesional, haciendo hincapié en la importancia de los valores éticos y morales de nuestra profesión, nuestra fuerza se sustenta en la vocación de servicio, el respeto al enfermo y el interés en progresar como personas y profesionales.

El haber presidido la Asociación Argentina de Cirugía (AAC) es uno de los honores más grandes que se puede recibir como cirujano y, además, una enorme responsabilidad.

Hoy, con más de 4000 socios, su misión continúa vigente. Esta tarea requiere una Asociación fuerte y representativa, con espíritu federal, que reúna a la mayoría de los cirujanos argentinos.

Durante el presente año proseguimos la tarea comenzada en ejercicios anteriores. Hemos creado la Comisión Gremial para la defensa y la lucha por los derechos laborales del cirujano, y el cobro de honorarios justos. Continuamos con la integración de los Capítulos dividiendo el país en 5 regiones para organizar problemáticas similares, afianzando nuestra relación con los Capítulos, y reformamos nuestro nomenclador llevándolo a 10 niveles; asimismo se han solucionado zonas de conflicto participando activamente en las negociaciones.

En el aspecto académico hemos continuado con el programa federal de formación en endoscopia flexible, con récord de inscriptos y cursos hands on a lo largo de todo el país. Además se pusieron en marcha el programa de mejora continua en Cirugía bariátrica y metabólica, el programa de simulación en cirugía y el programa de liderazgo en cirugía.

Por su parte, nuestra Revista ha sido incorporada al Núcleo Básico de Revistas Científicas Argentinas del CAYCIT-CONICET que, junto con el Portal SciELO, constituye el más importante índice a nivel nacional y regional.

Al iniciar mi gestión en la Presidencia tomé el compromiso de continuar con el desarrollo de los proyectos existentes y poner en marcha los nuevos que he mencionado anteriormente, pero fundamentalmente sobre la base del consenso. En definitiva, mirar al fu- turo honrando nuestra historia, ya que los hombres pasamos, pero las Instituciones quedan. Espero haber cumplido con mi compromiso y haber dejado en esta gestión el sello del consenso y la armonía.

Ya finalizando mi función como Presidente de la Asociación quiero agradecer y destacar el compromiso, la dedicación y responsabilidad de todo el personal de la Institución, representado en la persona del Director Dr. Martín Mihura, del Dr. José Luis Tortosa y de la señora María Inés Boquete.

Además, agradecer a los miembros de la Comisión Directiva, por su apoyo durante toda la gestión, y a los integrantes de los distintos Comités y Comisiones por las actividades desarrolladas.

Finalmente, nuestro Congreso ha ido creciendo en importancia y trascendencia y es el producto anual más importante de la actividad académica de la AAC.

Me corresponde ahora el honor de presentar al Presidente del $88^{\circ}$ Congreso Argentino de Cirugía, el Profesor Dr. Juan E. Álvarez Rodríguez.

Juan nació el 29 de diciembre de 1946 en el Hospital Italiano de La Plata. Sietemesino y mellizo con su hermana Blanca. Son los menores de cuatro hermanos de los cuales Justo fue el mayor, con cinco años de diferencia, y Eva con dos.

Su padre, Justo Lucas Álvarez Rodríguez, era abogado y oriundo de Junín, Pcia. de Buenos Aires. Su madre, Blanca Amelia Duarte, había nacido en Bragado, era maestra y conoció a su padre cuando residía con su familia en Junín.

Los Álvarez Rodríguez por aquel entonces eran bastante conocidos en dicha ciudad, pues un hermano de su padre, José Álvarez Rodríguez, también abogado, fue el primer Rector del Colegio Nacional de Junín, que actualmente lleva su nombre, así como la calle frente a su entrada principal.

Su nacimiento en la ciudad de La Plata fue una circunstancia relacionada con motivos laborales de su padre, que en esos años se desempeñaba como Ministro de Gobierno de la Provincia de Buenos Aires.

En 1947 se radicaron en la ciudad de Buenos $\mathrm{Ai}$ res, en el barrio de Flores, cuando su padre asumió como Ministro de la Corte Suprema de Justicia de la Nación. La niñez de Juan se desarrolló en un marco familiar de fuerte impronta política, cuya influencia marcó una etapa en la historia de la Nación. 
Su madre, mientras tanto, se desempeñaba en el Ministerio de Educación en la Dirección Nacional de Jardines de Infantes, siendo una de las promotoras de la incorporación temprana de los niños al sistema educativo en el ciclo preescolar. La muerte prematura de su padre, a los 50 años, dejó el comando de la familia a cargo de su madre, quien fue la encargada de controlar y promover el desarrollo y la educación de sus cuatro hijos.

Su primer colegio fue la Escuela Normal $\mathrm{N}^{\circ} 4$, a la que ingresó en el Jardín de Infantes por el término de dos años. Posteriormente, al iniciar el Ciclo Primario, se incorporó al Colegio Manuel Belgrano de los Hermanos Maristas, donde cursó los primeros años hasta que, en 1955, su familia debió trasladarse a Chile. Vivieron en la ciudad de Santiago dos años y medio, de donde guarda un grato recuerdo tanto por el lugar como por la hospitalidad de su gente. En ese tiempo, su madre decidió aprovechar la circunstancial adversidad para promover que estudiaran asiduamente y fue así como, a su regreso a Buenos Aires, volvió al Colegio Manuel Belgrano, de donde había salido en $3^{\text {er }}$ grado, para incorporarse al $2^{\circ}$ año del Ciclo Secundario a los 11 años de edad. La adaptación no fue fácil entre sus excompañeros que cursaban $6^{\circ}$ grado y los nuevos, dos a tres años mayores que Juan.

A los 15 completó el Curso de Ingreso a Medicina en la Universidad de Buenos Aires (UBA) y el ingreso a la Escuela Superior de Bellas Artes Prilidiano Pueyrredón. Su vocación por la Medicina la fue descubriendo con el correr de los años.

Finalizó su carrera en diciembre de 1968, con Diploma de Honor, poco antes de cumplir los 22 años. Durante su transcurso fue Auxiliar Docente como ayudante Honorario de la III Cátedra de Anatomía y Ayudante de la $1^{\text {a }}$ Cátedra de Patología. Al año siguiente hizo el Servicio Militar Obligatorio, en el Htal. Militar Central Cirujano Mayor Dr. Cosme Argerich, y fue dado de baja a los 8 meses como dragoneante.

En 1970 ingresó como Médico Residente de Cirugía en el Hospital Municipal Dr. Cosme Argerich. Fue Residente, Jefe e Instructor de Residentes, para luego incorporarse como Médico Suplente de Guardia y con posterioridad como Médico de Planta del Servicio de Cirugía.

Sus jefes fueron los Dres. Andrés Santas, Clemente Morel, Juan José Fontana y Alejandro Oría. Con este último tuvo una estrecha relación, pues fueron amigos y compañeros de Residencia.

A lo largo de los años intervino en diversos Comités del hospital, como el de Docencia e Investigación, el de Farmacia y el de Bioética. En el año 1994 fue Jefe de Unidad de Cirugía, y en 2012, al retirarse el Dr. Oría, asumió como Jefe del Servicio.

Bajo el liderazgo de Alejandro Oría y junto a sus compañeros de Servicio, trabajó fundamentalmente en la patología hepatobiliopancreática, logrando que el Hospital Argerich fuera un centro de referencia en la patología del páncreas. Fue así como Juan, junto a J. J. Fontana, A. Oría, L. Chiappetta y C. Ocampo, fueron honrados como Relatores Oficiales en distintos Congresos de Cirugía.

En particular, y con Carlos Ocampo y Hugo Zandalini, introdujeron el intervencionismo percutáneo no vascular en manos de cirujanos, una disciplina propia de la radiología intervencionista.

En el $66^{\circ}$ Congreso Argentino de Cirugía de 1995 fue Relator Oficial del tema "Procedimientos invasivos no quirúrgicos en patología abdominal de urgencia". Con motivo de este evento asistió como Fellow al Servicio de Radiología Intervencionista en el Hospital Universitario de San Diego, California, por invitación del Dr. Horacio D’Agostino.

La incorporación del primer ecógrafo del hospital al Servicio de Cirugía en 1986 los familiarizó con las imágenes seccionales del abdomen, permitió el desarrollo del intervencionismo e incorporó la ecografía como una herramienta de uso habitual, de ahí en adelante, en la formación de los médicos residentes de Cirugía.

A lo largo de su carrera, participó activamente en numerosos Congresos, Jornadas de Cirugía y Cursos de Posgrado, así como tuvo la oportunidad de presentar y publicar trabajos científicos en revistas nacionales o extranjeras y participar en libros de la especialidad. De igual modo fue miembro de diversas sociedades científicas en nuestro país e integró la Comisión Directiva de varias de ellas, como la Sociedad Argentina de Gastroenterología (SAGE), la Academia Argentina de Cirugía y la Asociación Argentina de Cirugía.

Siempre continuó vinculado a la Facultad de Medicina de la UBA, siendo Auxiliar Docente Honorario y Rentado de la VI Cátedra de Cirugía en el Hospital Argerich. Luego de finalizar la carrera docente, obtuvo el Título de Doctor en Medicina en 1988 con una tesis calificada como sobresaliente sobre: "Evaluación clínica y hemodinámica de la derivación selectiva esplenorrenal distal". Fue Docente Autorizado en 1989, luego Profesor Regular Adjunto de Cirugía en 1998 y finalmente Profesor Regular Titular de Cirugía a partir de 2009. Paralelamente, hizo una Maestría en Salud Pública en la Universidad del Salvador y egresó con una tesina también calificada como sobresaliente.

En el año 2010 fue elegido Consejero Titular por el Claustro de Profesores de la Facultad de Medicina de la UBA por el período 2010-2014. Designado como Secretario General de la Facultad de Medicina, a partir de 2012 hasta 2014, y desde ese año hasta 2018 fue integrante del Consejo de Orientación y del Consejo Departamental de Cirugía de la Facultad de Medicina. Actualmente ejerce la Dirección de este Consejo Departamental.

Se jubiló como Jefe de la División Cirugía General del Hospital Cosme Argerich en diciembre de 2015, y fue designado Profesor Consulto Titular de Cirugía en el corriente año. 
En su actividad extrahospitalaria fue cirujano en diversas instituciones, como el Ministerio de Hacienda, el Sanatorio Güemes, la Obra Social para la Actividad Docente (O.S.P.L.A.D), la Obra Social para la Industria Textil, y Director Médico de la Obra Social para la Industria Metalúrgica.

Si bien Juan dice que nunca fue un deportista, los archivos fotográficos no lo dejan mentir. Hizo el Curso de Timonel Técnico de Navegación a Vela del Instituto Nacional de Deportes, y es un eximio jinete: practica equitación los fines semana.

Juega muy bien al tenis. Dice Juan que su casa, en el Náutico de Escobar, es el lugar ideal de descanso y el ambiente propicio para disfrutar de las actividades deportivas y compartir los afectos.

En cuanto a su familia, tiene cuatro hijas; Constanza, Pilar y María son las tres mayores; la menor de todas, Eugenia, que acaba de cumplir 4 años, es el mejor regalo que a esta altura de su vida le ha dado su actual mujer, Ingrid, quien, por si fuera poco, además es MAAC.

Para finalizar quiero agradecer a esta hermosa profesión y a la AAC por haberme dado la oportunidad de conocer y entablar una genuina amistad con Juan Álvarez Rodríguez, que es un profesional excepcional y un ser humano con valores ejemplares, por lo que ha sido para mí un gran honor haberlo presentado. Muchas gracias. 